Volume 3

Issue 4 -- Cardiovascular Aging

Article 19

$11-11-2016$

\title{
Cost-Effectiveness of Genomic-Based Warfarin Therapy
}

John Weissert

Kourosh Ravvaz

Follow this and additional works at: https://aah.org/jpcrr

Part of the Cardiology Commons, Cardiovascular Diseases Commons, Community Health and Preventive Medicine Commons, and the Health Services Research Commons

\section{Recommended Citation}

Weissert J, Ravvaz K. Cost-effectiveness of genomic-based warfarin therapy. J Patient Cent Res Rev. 2016;3:240.

Published quarterly by Midwest-based health system Advocate Aurora Health and indexed in PubMed Central, the Journal of Patient-Centered Research and Reviews (JPCRR) is an open access, peer-reviewed medical journal focused on disseminating scholarly works devoted to improving patient-centered care practices, health outcomes, and the patient experience. 
usage data. By potentially avoiding a diagnosis of HIT/HITT in these patients, the hospital would realize an annualized savings of over $\$ 86,000$.

Conclusion: Normal saline has demonstrated historical noninferiority to heparin for maintaining PICC patency when used as the capping solution with positive pressurized caps. Similar results were found during our pilot.

\section{Cost-Effectiveness of Genomic-Based Warfarin Therapy}

John Weissert, Kourosh Ravvaz

\section{Aurora Research Institute}

Background: With over 40 years of demonstrated clinical efficacy, warfarin remains the world's most used pharmaceutical to prevent ischemic stroke in patients with atrial fibrillation (AF). However, warfarin has many challenges. Thus, despite known effectiveness, warfarin is a leading cause to druginduced morbidity and mortality. Over 50 different warfarin therapy protocols, including a number of pharmacogenomicbased (PG) protocols, with as many as 14 independent variables, have been developed to improve safety and efficacy, thereby reducing ischemic strokes and intracranial hemorrhages (ICH). Purpose: To conduct a preliminary cost-effectiveness study to determine the price point at which using warfarin PG dosing to prevent ischemic stroke and ICH would provide a neutral cost difference for the AF patient population at Aurora Health Care. Methods: Using a 15-year retrospective electronic medical record, we generated a large enough simulated AF population using Bayesian Network modeling to conduct a series of simulated warfarin therapies. We used five different PG and non-PG warfarin therapy protocols. The protocols with various levels of personalization used different PG and non-PG dosing algorithms for initial, adjustment and maintenance warfarin dosing. The simulation platform was able to predict daily international normalized ratio values and the rate of ischemic stroke and ICH in each simulated patient over 90 days for each of the five warfarin therapy protocols. Using nationwide estimates derived through literature review, we estimated the total cost of administering warfarin using the five different protocols and subsequent acute and 5-year care costs (adjusted according to annual Medical Care Component of the Consumer Price Index).

Results: In 2000-2015, a total of 48,006 patients, or $\sim 3,000$ patients annually, initiated warfarin therapy with a primary diagnosis of AF at Aurora. We found that Aurora's current best practice warfarin therapy protocol had the highest predicted costs for ICH, resulting in $\$ 163,462.55$ for acute care costs (averaged over 1,000 patients) and $\$ 171,279.60$ for 5-year ongoing care related to ICH. The current Aurora protocol also had the highest associated costs for ischemic stroke at $\$ 51,333.45$ for acute care and $\$ 58,507.21$ for 5-year ongoing care. In contrast, PG-protocol 3, which incorporated patient's genotype into the warfarin dosing protocol, had the lowest predicted acute care and ongoing costs associated with ICH at $\$ 119,823.78$ for acute care and $\$ 125,462.75$ for ongoing care.
For 1,000 AF patients initiating warfarin therapy in Aurora, switching to a PG protocol would save $\$ 55,299.94$ in acute care costs and $\$ 59,198.50$ in 5-year ongoing care.

Conclusion: At a cost of $\$ 59.20$ per patient, warfarin PG dosing is cost neutral. With substantial decreases in genotyping cost in recent years, it is likely this price is currently achievable. Therefore, although there is only incremental clinical benefit from warfarin PG dosing, it is likely cost-effective.

\section{Identifying Disparities in Colorectal Cancer Screening Rates in Milwaukee-Based Academic and Nonacademic Clinics}

Jasmine Wiley, Jonathan J. Blaza, Will Lehmann, Deborah Simpson, Jeffrey A. Stearns, Shelby L. Pischke, Tracy L. Greiten

Department of Family Medicine, Aurora Health Care; Department of Family Medicine, Aurora UW Medical Group; Academic Affairs, Aurora UW Medical Group; Business Intelligence, Aurora Health Care; Operational Informatics, Aurora Health Care

Background: The Institute for Healthcare Improvement's Triple Aim focuses on improving the patient's experience of care, improving population health and reducing the per capita cost of health care. Health care systems and providers continuously seek to improve quality of care through understanding what percentage of their patients are achieving quality-of-care standards for various indicators, including immunizations, tobacco cessation, asthma and cancer screening. As health care moves toward reimbursing for value-based care, deepening our understanding of patient population characteristics within each of these conditions is vital to continuous quality improvement. Purpose: To determine if there are race/ethnicity/age/preferred language (REAL) disparities in care to patients 50 years old or older who are eligible for colorectal cancer (CRC) screening in family medicine residency clinics.

Methods: A retrospective analysis of all patients eligible for CRC screening at two Milwaukee-based family medicine residency teaching clinics (referred to as FM1 and FM2) and nonacademic clinics in greater Milwaukee (NAC-MKE) during a 12-month period (December 2014 - November 2015) was undertaken in collaboration with health care system quality improvement specialists. Percentage of patients achieving CRC screening metric was reported by REAL and gender. As the ultimate goal was to identify subpopulations to target for improvement, categories with $\mathrm{N}<25$ were omitted and criterion for disparity within a category was defined as $>10 \%$.

Results: The largest CRC screening disparity was associated with age, with gaps ranging from $13 \%$ to $15 \%$ between populations $>65$ years old versus 50-54 years old: NAC-MKE (79\% vs 66\%), FM1 (81\% vs 68\%), and FM2 (80\% vs 65\%). CRC screening disparities varied by black/African-American race per location, 54\% at NAC-MKE and 67\% at FM2 (N $\leq 25$ at FM1). Other race, ethnicity and gender were $<10 \%$.

Conclusion: Per the Centers for Disease Control and Prevention, the African-American/black race has the highest 